\title{
Precipitable water characteristics during the 2013 Colorado flood using ground-based GPS measurements
}

\author{
Hannah K. Huelsing ${ }^{1,2}$, Junhong Wang ${ }^{2}$, Carl Mears ${ }^{3}$, and John J. Braun ${ }^{1}$ \\ ${ }^{1}$ Constellation Observing System for Meteorology, Ionosphere, and Climate Program Office, University Corporation for \\ Atmospheric Research, 3300 Mitchell Lane, Boulder, CO 80301, USA \\ ${ }^{2}$ Department of Atmospheric and Environmental Sciences, University at Albany, SUNY, 1400 Washington Avenue, Albany, \\ NY 12222, USA \\ ${ }^{3}$ Remote Sensing Systems, 444 10th Street, 200 Santa Rosa, CA 95401, USA \\ Correspondence to: Hannah K. Huelsing (huelsing@ucar.edu)
}

Received: 21 December 2016 - Discussion started: 14 February 2017

Revised: 25 August 2017 - Accepted: 9 September 2017 - Published: 1 November 2017

\begin{abstract}
During 9-16 September 2013, the Front Range region of Colorado experienced heavy rainfall that resulted in severe flooding. Precipitation totals for the event exceeded $450 \mathrm{~mm}$, damages to public and private properties were estimated to be over USD 2 billion, and nine lives were lost. This study analyzes the characteristics of precipitable water (PW) surrounding the event using 10 years of high-resolution GPS PW data in Boulder, Colorado, which was located within the region of maximum rainfall. PW in Boulder is dominated by seasonal variability with an average summertime maximum of $36 \mathrm{~mm}$. In 2013, the seasonal PW maximum extended into early September and the September monthly mean PW exceeded the 99th percentile of climatology with a value $25 \%$ higher than the 40-year climatology. Prior to the flood, around 18:00 UTC on 8 September, PW rapidly increased from 22 to $32 \mathrm{~mm}$ and remained around $30 \mathrm{~mm}$ for the entire event as a result of the nearly saturated atmosphere. The frequency distribution of September PW for Boulder is typically normal, but in 2013 the distribution was bimodal due to a combination of above-average PW values from 1 to 15 September and much drier conditions from 16 to 30 September. The above-normal, near-saturation PW values during the flood were the result of large-scale moisture transport into Colorado from the Tropical Eastern Pacific and the Gulf of Mexico. This moisture transport was the product of a stagnating cutoff low over the southwestern United States working in conjunction with an anticyclone located over the southeastern United States. A blocking ridge located over the Canadian Rocky Mountains kept both of the synoptic fea-
\end{abstract}

tures in place over the course of several days, which helped to provide continuous moisture to the storm, thus enhancing the accumulated precipitation totals.

\section{Introduction}

During 9-16 September 2013, multiple local and state precipitation records were broken when low-level easterly flow interacted with an anomalous moisture pool over the Front Range region of Colorado to produce one of the largest floods in state history (Colorado Climate Center, 2013). The heaviest and most persistent rainfall occurred on 11 and 12 September, with a maximum centered over Boulder and Larimer counties (Fig. 1). In the hardest hit areas, total precipitation accumulation exceeded $450 \mathrm{~mm}$ (17.7 in) (Gochis et al., 2015). The city of Boulder set multiple records, observing $292.6 \mathrm{~mm}$ over the course of 2 days and $341.8 \mathrm{~mm}$ over the course of 3 days. The resultant flooding claimed nine lives and caused 1100 documented landslides. Damages to public and private properties were estimated to be over USD 2 billion (Gochis et al., 2015).

The following summary of the September 2013 event was first presented in Gochis et al. (2015). Surface temperatures were in the $16-18^{\circ} \mathrm{C}\left(60-64^{\circ} \mathrm{F}\right)$ range and precipitable water $(\mathrm{PW})$ values were high. Periods of heavy precipitation exceeding $25 \mathrm{~mm}$ ( 1 in.) per hour, along with flooding, began on the evening of 11 September, with the heaviest portions over the Front Range, the area outlined in Fig. 1. The 
(a)
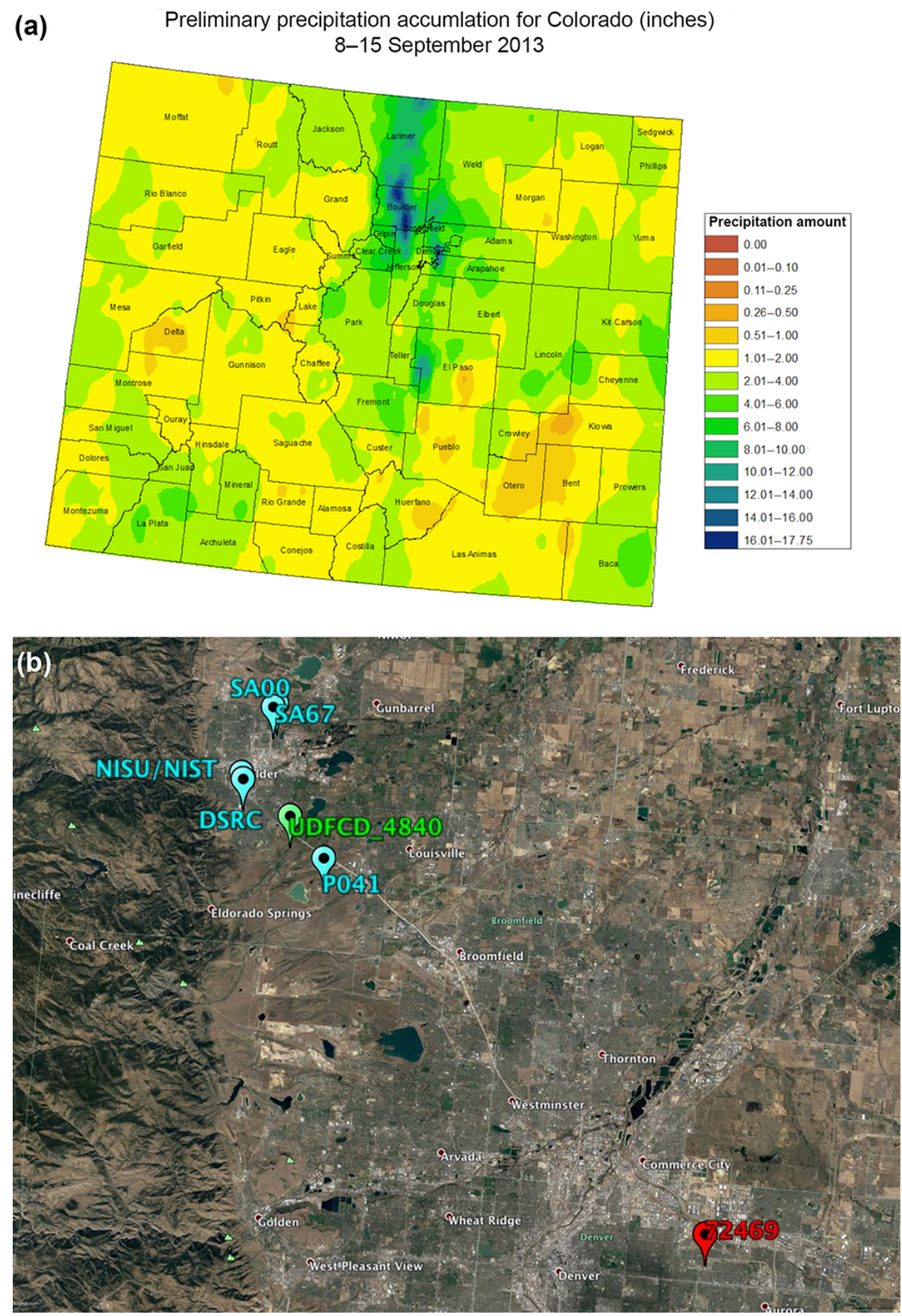

Figure 1. (a) Map of accumulated precipitation over Colorado from 8 to 15 September 2013 (image courtesy of the Colorado Climate Center); (b) the locations of the primary GPS (blue circles), rain gauge (green circle), and radiosonde (red circle) observations used in this study. NISU and NIST are the only IGS GPS stations plotted on this map. All of the other GPS stations are from the SuomiNet network.

mountainous region between Boulder and Estes Park experienced the heaviest rain rates, which ranged from 25 to $50 \mathrm{~mm}$ (1-2 in) per hour and resulted in an overnight total exceeding $200 \mathrm{~mm}$ (8 in). Somewhat lighter rainfall continued into 12 September, becoming intense once more during the afternoon hours and increasing rainfall totals to over $380 \mathrm{~mm}$ (15 in) in the Boulder to Estes Park region. By 13 September, precipitation had finally lessened to intermittent showers and widespread drizzle, finally clearing on 14 September. A final surge of moisture occurred on the 15th and resulted in 25$50 \mathrm{~mm}(1-2$ in) of widespread, moderate rainfall on soils that were already saturated, thus increasing the amount of runoff.

This event was uncharacteristic, not only because of its rainfall amounts but also because of the time of year in which 
Table 1. A comparison of the September 2013 event to previous heavy, flood-inducing precipitation events in northern Colorado history. All monetary values were calibrated to 2013 values.

\begin{tabular}{|c|c|c|c|c|}
\hline Date & Location most affected & $\begin{array}{r}\text { Total rainfall } \\
(\mathrm{mm} \text { [in] })\end{array}$ & Deaths & $\begin{array}{r}\text { Cost } \\
\text { (USD) }\end{array}$ \\
\hline 1-12 September 1938 & Fort Collins & $203-254[8-10]$ & 6 & 7.5 million \\
\hline 4—9 Мay 1969 & West of Denver & $152-229[6-9]$ & 0 & 136.5 million \\
\hline 31 July-1 August 1976 & Estes Park & $305-356[12-14]$ & 144 & 348.5 million \\
\hline 27 July-4 August 1997 & Fort Collins & $368[14.5]$ & 5 & 290 million \\
\hline 29-30 April 1999 & Northern Colorado & $203-254[8-10]$ & 0 & 140 million \\
\hline 9-16 September 2013 & Boulder & $406[16]$ & 8 & 2 billion \\
\hline
\end{tabular}

it occurred. Petersen et al. (1999) examined the climatology of precipitation events over the Front Range region and found that, while a majority of events occur between April and October, the convective classification of the events differs depending on what time of year the convection occurs in. There are two peaks in the event distribution, the first of which occurs in late May to early June. Precipitation events during this time are synoptic-, or large-, scale and quasistationary. The precipitation in these events is enhanced orographically and locally and is typically widespread and of moderate intensity. The second peak in precipitation events occurs from late July into early September with a pronounced maximum frequency from late July into early August. The storms in these events generally have a small areal extent and are highly convective. The September 2013 event was quasistationary and synoptic with precipitation controlled by localized and orographic enhancements. The areal extent of the 2013 event was large and the rainfall was of moderate intensity. According to the climatology completed by Petersen et al. (1999), this type of event was more typical of storms which occur in late May to early June. However, this event occurred at a time of year when precipitation tends to be highly convective and of small areal extent, so the timing, as well as the amount of rainfall, was abnormal.

In another study which examined the climatology of rainfall events in Colorado, Mahoney et al. (2015) found that the region of Colorado east of the Continental Divide does not generally experience heavy precipitation events in the fall because it is during this time of year that the region experiences seasonal atmospheric drying. They did note that there was enhanced climatological variability in September and October, making it difficult to place these months into the same category as the drier months (November-February). In general, east of the Continental Divide experiences most of its precipitation in the spring and summer months, with the Front Range receiving a majority of its moisture in the spring. However, extreme precipitation events are not limited to these seasons and can also occur in fall and winter months.

Flooding due to extreme precipitation events can occur at any time of the year because all elevations in all seasons are prone to experiencing heavy precipitation. This is par- tially represented by the dates in Table 1 , which compares the September 2013 event to previous heavy precipitation events in northern Colorado history that resulted in catastrophic flooding (Colorado Climate Center, 2013; Maddox et al., 1977; Petersen et al., 1999; Gochis et al., 2015). Prior to the September 2013 event, there were five events on record that were classified as comparable to the 2013 event by the Colorado Climate Center. However, all except one of these storms took place in the spring and summer months, as would be expected from the climatology of the rainfall events presented in earlier.

Out of the events listed in Table 1, the Colorado Climate Center noted that the event that occurred on 1-12 September 1938 near Fort Collins, Colorado, was the most similar in timing and magnitude to the September 2013 event. Observers recorded $203-254 \mathrm{~mm}(8-10$ in) of rainfall and the surrounding region experienced severe flooding. However, there is not much else known about this event because the amount of recorded atmospheric data available from this time period is limited. Comparing the September 2013 event to the five previous events in Table 1, this event had the highest total rainfall and caused the most damage, as is seen by the total cost of the event. This event also had a vast areal coverage, with heavy precipitation occurring from Denver all the way into southern Wyoming. Flooding took place as far to the east as Nebraska and caused a lot of damage to infrastructure along the Front Range of Colorado.

The amount of precipitation that fell during the September 2013 event required a large amount of moisture at a time of year when atmospheric moisture climatologically begins to decrease from higher summer values to lower winter values (Mahoney et al., 2015). This uncharacteristic increase in moisture implies moisture was transported into the region. When moisture converges at the surface, it is transported to higher levels assuming there is sufficient atmospheric instability, which is usually greater over orography (Graham et al., 2012). The interaction of low-level moisture with orography results in convection and the production of precipitation (Guerova et al., 2016). Adams et al. (2013) found that water vapor convergence, which results in heavy precipitation generally occurs approximately an hour prior to the event. They 
also found that the stronger the convergence is, the more intense the precipitation. Sapucci et al. (2016) found that after PW peaked, rainfall began and PW decreased.

Such characteristics are important to understand because they could influence future weather and climate trends. Kunkel et al. (2013) found an increasing trend in atmospheric PW quantities associated with extreme precipitation events and suggested this trend could lead to an increase in storm intensity. While Hoerling et al. (2014) noted that the September 2013 event was probably not connected to climate change, they did find that heavy precipitation events are becoming more frequent and Karl and Trenberth (2003) found evidence that the number of heavy precipitation events is expected to increase with increasing global temperatures, such as we are experiencing now. The observed and projected increase in the number of heavy precipitation events, combined with the uncertainty of how PW contributes to characteristics of these events, motivated an investigation of PW characteristics surrounding the 2013 event so as to better understand the contributions of PW to an extreme precipitation event with the objective to someday apply these results to future research incorporating a wider variety of events.

As the aim of this research was to examine the characteristics of atmospheric PW during the 2013 Colorado flood, data with a high spatial and temporal resolution were needed to resolve features within the event. GPS receivers are much more densely spaced with a total of 236 stations over North America than the radiosonde network, which has a total of 92 stations. The higher density of observations in the GPS network results in a higher spatial resolution with which to analyze storm features and water vapor transport. GPS data also have a much higher temporal resolution of anywhere from $30 \mathrm{~min}$ to $2 \mathrm{~h}$, as compared to the standard, twice-daily launching of radiosondes.

The primary goal of this research was to investigate the magnitude and characteristics of PW over the Front Range region associated with the September 2013 event. The goal of this study was to answer the following scientific questions.

1. What were the characteristics of PW surrounding this event? This portion of research was focused on the examination of the temporal variability of PW, as well as a comparison with climatology, before, during, and after the event.

2. Where did the moisture for the 2013 event originate? To answer this question, synoptic-scale dynamics and pre-existing conditions that led to large-scale, continuous moisture transport were evaluated.

\section{Data and methodology}

\subsection{Precipitable water datasets}

Two datasets were used to analyze PW characteristics surrounding the 2013 event. The first of these was a 2-hourly, long-term (1995-2015) PW dataset (Wang et al., 2007; Mears et al., 2015, 2017). The PW in this dataset is derived using 5 min International Global Navigation Satellite System (GNSS) Service (IGS) zenith total delay (ZTD) data. The analysis technique for the interpolation and conversion of ZTD to PW is summarized in Wang et al. (2007) and two key variables used in the conversion are water-vapor-weighted atmospheric temperature $\left(T_{\mathrm{m}}\right)$ and surface pressure $\left(P_{\mathrm{s}}\right)$. ZTD is represented as the sum of the zenith hydrostatic delay, which is a function of $P_{\mathrm{S}}$, and the zenith wet delay, which is a function of PW and $T_{\mathrm{m}}$. The 2-hourly PW data from Boulder became available starting in 2004. In this study, IGS data were used for analysis only in Sect. 3 .

The second PW dataset used in Sects. 3 and 4 of this study was the $30 \mathrm{~min}$ SuomiNet dataset from the Constellation Observing System for Meteorology, Ionosphere, and Climate (COSMIC) group (Ware et al., 2000). The SuomiNet network currently consists of over 200 sites located around North America and the data are processed in near-real time from raw GPS data, the values of which do not differ greatly from post-processed GPS data. For Sect. 4 of this research, the standardized anomalies of the SuomiNet data were calculated by subtracting PW at each time step from the mean and dividing this by the standard deviation (Grumm and Hart, 2001). The standardized anomaly data were gridded and interpolated using a general kriging method to a grid box of $0.5^{\circ} \times 0.5^{\circ}$. Kriging is defined as optimized interpolation that is weighted by spatial covariance values and based on regression against observed values of surrounding data points (Bohling, 2005). This method was chosen because of its simplicity and superior performance when compared with the inverse distance weighting (IDW) method (Zimmerman et al., 1999; Yasrebi et al., 2009).

\subsection{Formulation of a GPS PW Climatological Dataset}

PW data for Boulder, Colorado, were chosen to evaluate the PW variability of this region over the course of 10 years and compare this variability with that of 2013 to improve the understanding of how the September 2013 event differed from climatology. This region encompasses six SuomiNet stations and two IGS stations (Fig. 1b and Table 2). To examine the anomalous nature of the flood, a dataset with a length of at least 10 years of observations was needed as a climatological standard for the analyzed region. While 10 years is not long enough for a standard climatology of 30 years as defined by the World Meteorological Organization (WMO), GPS PW data for Boulder have only been available since 2004. The PW time series of each GPS station was initially examined 
Table 2. The geographic and topographic information of the primary GPS, rain gauge, and radiosonde stations used in this study.

\begin{tabular}{lcccl}
\hline Station name & $\begin{array}{c}\text { Latitude } \\
\left({ }^{\circ} \mathrm{N}\right)\end{array}$ & $\begin{array}{c}\text { Longitude } \\
\left({ }^{\circ} \mathrm{W}\right)\end{array}$ & $\begin{array}{c}\text { Altitude } \\
(\mathrm{m})\end{array}$ & $\begin{array}{l}\text { Type of } \\
\text { station }\end{array}$ \\
\hline 72469 & 39.77 & -104.87 & 1625 & Radiosonde \\
DSRC & 39.99 & -105.26 & 1669 & GPS \\
NISU/NIST & 39.99 & -105.26 & 1649 & GPS \\
P041 & 39.95 & -105.19 & 1743 & GPS \\
SA00 & 40.04 & -105.24 & 1623 & GPS \\
SA67 & 40.04 & -105.24 & 1623 & GPS \\
UDFCD_4840 & 39.97 & -105.22 & 1646 & Rain gauge \\
\hline
\end{tabular}

to determine which, if any, station had a long enough data record to serve as the climatological standard and also to check for data outliers and data continuity. No stations were found to have more than 7 years of data and datasets that contained discontinuities were discarded. A major issue that appeared during this analysis was that only one SuomiNet and one IGS station had data observations during the September 2013 event, and neither of them had a lengthy dataset. A decision was made to combine the data from different stations in the region and make a 10-year dataset that included observations from the flood.

The GPS PW data used to create the 10-year dataset were first quality-controlled by using several methods defined in Wang et al. (2007). The first method used was the range test in which the lower and upper limits of PW values were set as 0 and $150 \mathrm{~mm}$, respectively. The second quality-control method used involved using the mean and standard deviation for each month to detect any outliers. This method required that at least one-quarter of the data be present in order to have an adequate amount of observations so that the statistical aspects could be deemed accurate. Individual PW values within each month were analyzed and any values that were more than 4 standard deviations away from the monthly mean were discarded (Wang et al., 2007). The quality control removed $0.1 \%$ of the total data points for the station SA00 and less than $0.1 \%$ of the total data points for the rest of the stations.

The next step in the creation of the 10-year dataset was to compare PW data among the stations. PW is strongly dependent on elevation so any station that had an elevation above $1800 \mathrm{~m}$ was eliminated because these receivers were located too far above the elevation of Boulder $(1655 \mathrm{~m})$. To remain consistent, the remaining stations were compared to the station with the longest dataset and elevation closest to that of Boulder (DSRC). Five stations were chosen for the merged 10-year PW dataset (Fig. 2) because their averaged PW differences were not statistically significant from one another and the elevation differences between all stations were less than $50 \mathrm{~m}$. A more thorough analysis of the complete dataset and its comparison with 2013 is described in Sect. 3. The SuomiNet station, P041, also passed the statistical signifi-

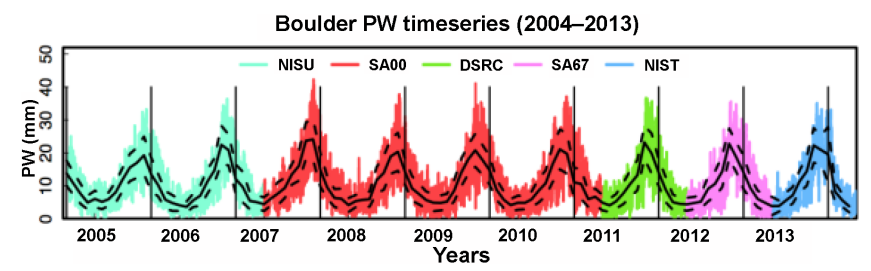

Figure 2. A time series of the GPS PW data for Boulder, Colorado, from 2004 to 2013 with each station denoted by a different color, the monthly means denoted by the solid black line, and \pm 1 standard deviation denoted by the horizontal black dashed lines. September of each year is represented by the vertical black lines.

cance test but did not have a complete record of data for 2013 so could not be included in the 10-year dataset. Instead, the 2013 PW data from P041 were used to analyze small-scale variability leading up to, and during, the flood period because it has a higher temporal resolution $(30 \mathrm{~min})$ than NIST (2hourly), which was chosen for the 10 -year dataset.

\subsection{Additional datasets}

The data used as a long-term PW climatology dataset were twice-daily radiosonde data from the Stapleton airport in Denver, Colorado, extracted from the homogenized radiosonde dataset created by Dai et al. (2011). This PW dataset was created by integrating specific humidity from the surface to $100 \mathrm{hPa}$, is available from 1979 to 2013 , and was homogenized using an advanced statistical approach that is more thoroughly described in Dai et al. (2011).

The primary dataset used to evaluate moisture transport was the North American Regional Reanalysis (NARR) dataset, which is available from 1979 to the present (Mesinger et al., 2006). The domain for NARR is North America and the horizontal resolution is $32 \mathrm{~km}$ with 45 vertical layers. The NARR variables chosen for the evaluation of moisture transport surrounding the event were the $500 \mathrm{hPa}$ geopotential height and the vertically integrated moisture flux.

\section{Precipitable water characteristics}

Gochis et al. (2015) noted that the atmosphere over northern Colorado was abnormally moist from 9 to 16 September. Radiosondes captured PW values above $30 \mathrm{~mm}$, an abnormal value for a semiarid climate. Gochis et al. (2015) also noted that the raindrop distribution during the event consisted of numerous small raindrops, which is more commonly observed in a tropical climate. To better understand how abnormal the atmospheric moisture was during this event, the magnitude, distributions, and variability of PW over Boulder were evaluated and compared to climatology. 


\subsection{Temporal variability of precipitable water}

First, the temporal characteristics of September of 2013 were compared with the 10-year GPS PW dataset described in Sect. 2.2. Figure 2 shows the time series of the merged 10year PW dataset discussed in Sect. 2. The strongest PW variation is seasonal with a mean seasonality of $18 \mathrm{~mm}$ and the summer peaks are coincident with the annual occurrence of the wet season in Colorado. Also note that the belted appearance of this time series represents synoptic and diurnal PW variability, the latter of which has an average magnitude of $8 \mathrm{~mm}$. The maximum value of PW for 2013 was $33.5 \mathrm{~mm}$ on 12 September. Note the extension of high PW values from the summer months into early September 2013. This extension is not observed in any of the other years contained in this dataset and is an indication that the atmosphere was anomalously moist for the time of year in which the flood occurred.

Figure 3 zooms in on the extension of high PW values observed in September 2013, giving a clearer view of the temporal variability of $\mathrm{PW}$ and precipitation surrounding the flood event. The high PW values up until 5 September represent moisture associated with the end of the North American Monsoon. These high values begin to decrease around 6 September before quickly rising on 9 into 10 September, with values spiking to above $30 \mathrm{~mm}$. PW decreases slightly to $26 \mathrm{~mm}$ until 11 September, when it once again increases to above $30 \mathrm{~mm}$ where it remains until 13 September. After this, PW decreases to values closer to the September climatological average of $15 \mathrm{~mm}$.

PW peaks approximately $1 \mathrm{~h}$ before rainfall begins, which is consistent with the findings of Adams et al. (2013) and Sapucci et al. (2016), both of which found that PW peaks between 32 and 64 min prior to the start of rainfall. The decrease of PW after the peak is associated with the condensation of PW as it makes the transition into precipitation (Van Baelen et al., 2011). Another point to take note of is precipitation begins after PW rises between 2 and 3 standard deviations above the PW long-term median, which was found in Foster et al. (2003).

PW values stay relatively constant during the event despite the fact that continuous, and sometimes heavy, precipitation is occurring. For PW to remain at high values over multiple days, as was seen here, moisture needed to be continuously transported into the region (Gimeno et al., 2012). Had there not been a constant transport of moisture, PW would have decreased as atmospheric moisture condensed and formed precipitation. The examination of the moisture transport that fueled this event is presented in Sect. 4.

\subsection{Precipitable water abnormality during the 2013 flood}

The consistently high values of PW during the time of heaviest precipitation in Fig. 3 led to an investigation to discern whether the atmosphere over Boulder was fully saturated

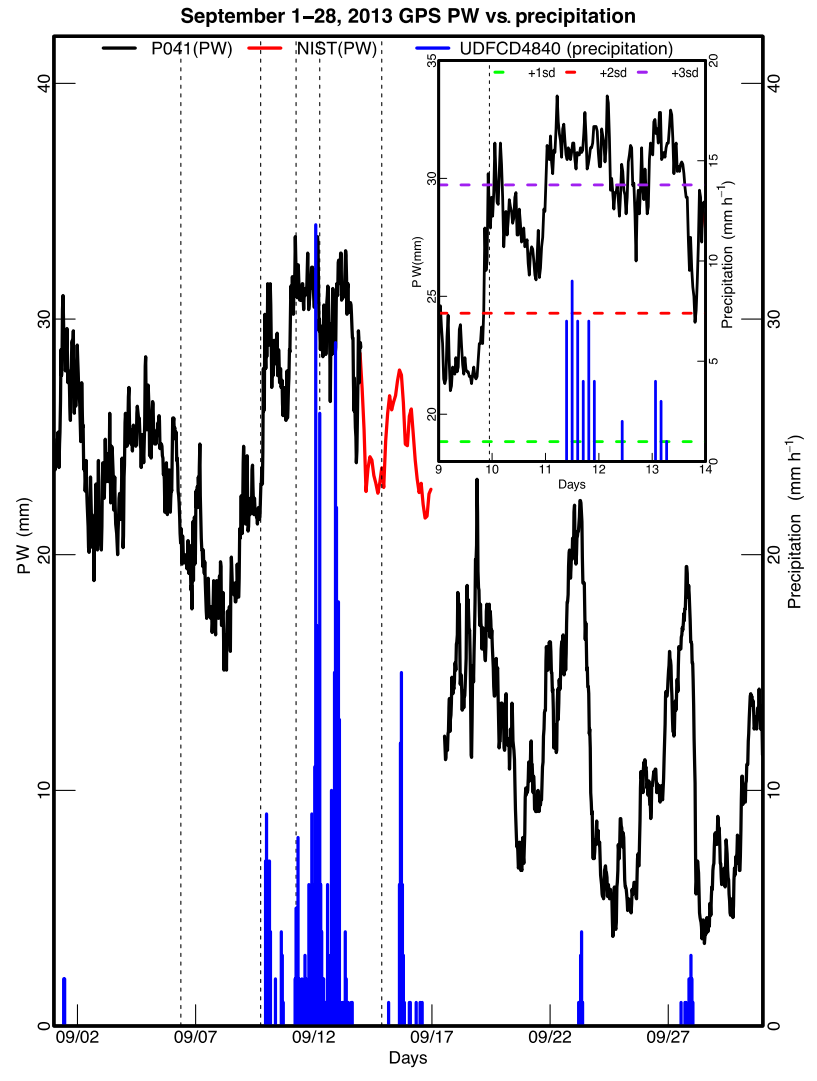

Figure 3. A time series of $30 \mathrm{~min}$ (station P041) and 2-hourly (station NIST) GPS PW compared with precipitation (rain gauge UDFCD4840) from 1 to 28 September 2013. The inserted graph compares the same variables from 9 to 14 September 2013 with the addition of green, blue, and red horizontal dashed lines indicating 1, 2 , and 3 standard deviations above the PW long-term median, respectively.

during the September 2013 event. To evaluate this, observed radiosonde $\mathrm{PW}$ data were compared with $\mathrm{PW}$ values that were calculated assuming a fully saturated atmosphere, i.e., $100 \%$ relative humidity from the surface up to $300 \mathrm{hPa}$. Note that a fully saturated atmosphere is an unrealistic assumption for a real atmosphere but can be used for simplified comparison. Figure 4 shows the comparison between these two variables from 6 to 20 September 2013. Starting on 10 September observed and fully saturated PW values were within $5 \mathrm{~mm}$ of each other, indicating an atmosphere that was very near to saturation during the course of the September 2013 event. Except for a period of time on 14 September when the atmosphere began to dry, observed PW stayed relatively close in value to the fully saturated PW until 16 September.

Figure 5 compares monthly-averaged 2013 radiosonde data and GPS data to 40 and 10 years of monthly-averaged radiosonde and GPS data, respectively. 2013 PW monthly averages were consistently lower than climatology until July while the Front Range was still under drought conditions 


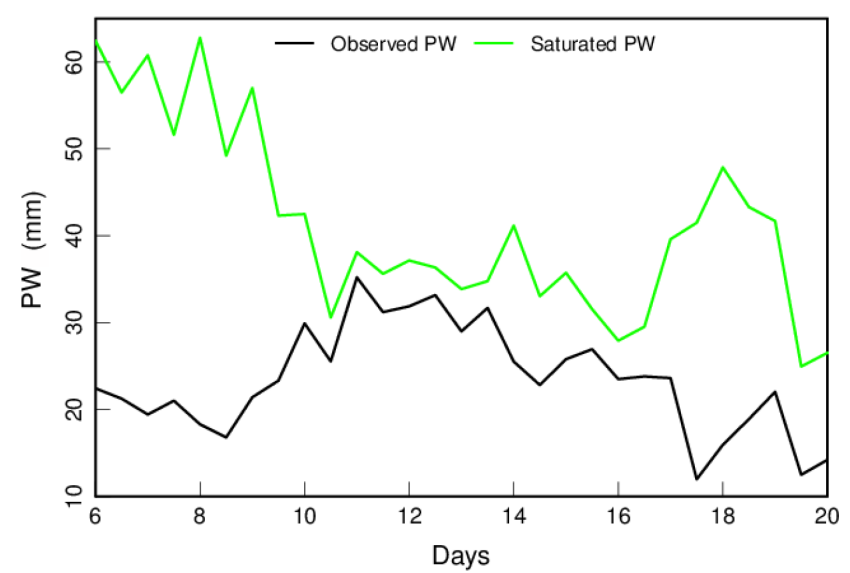

Figure 4. A time series comparison of observed radiosonde PW (black line) and saturated PW (green line) for 1-28 September 2013 over Denver, Colorado.

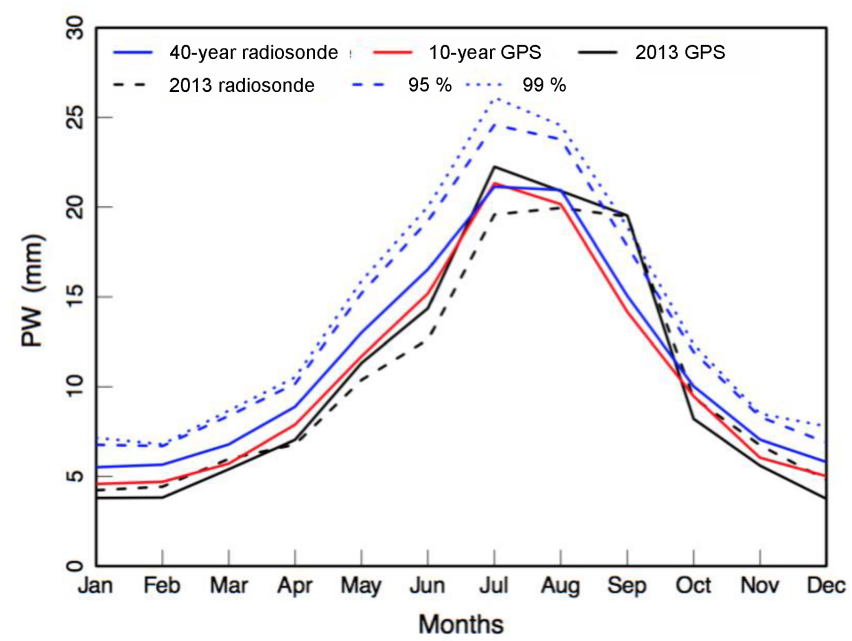

Figure 5. Monthly-averaged GPS PW (solid black line) and radiosonde data (dashed black line) for 2013 with the 10-year merged GPS PW dataset (solid red line) and the 40-year averaged radiosonde PW dataset (solid blue line). Additionally, there are the 95th (dashed red line) and 99th (dotted red line) percentiles for 10 years of GPS data and the 95th (dashed blue line) and 99th (dotted blue line) percentiles for 40 years of radiosonde data.

according to the National Climatic Data Center (NCDC) North American Drought Monitor. The monthly average for September of 2013 was around $20 \mathrm{~mm}$, approximately $25 \%$ higher than the long-term climatological monthly average for September. Also note that the monthly average for September of 2013 is above the 95th and 99th percentiles, which were calculated from 40 years of monthly-averaged radiosonde data. McKee and Doesken (1997) evaluated upper air data for extreme precipitation events for Colorado between 1958 and 1992 and found that PW from vertical soundings never exceeded the 95th percentile. That the monthly-averaged PW
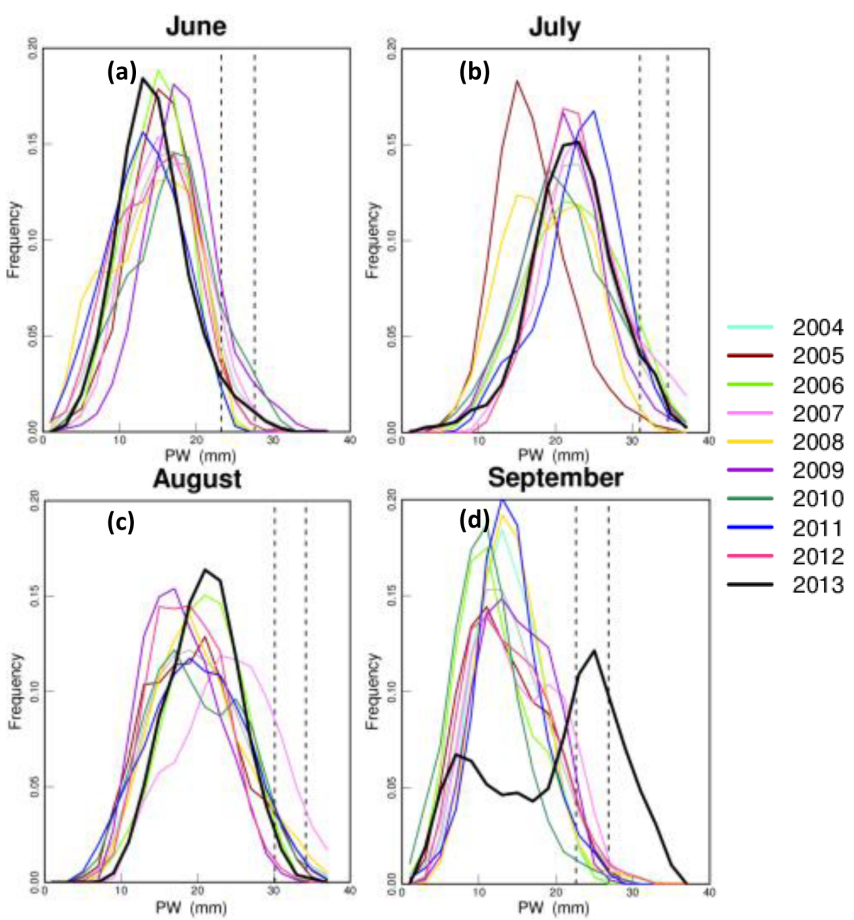

Figure 6. Statistical frequency distributions of GPS PW for JuneSeptember of 2004-2013 with the 95th percentile for 10 years of each month of data denoted by the left-most dashed line and the 99th percentile for 10 years of each month of data denoted by the right-most dashed line.

for September of 2013 exceeded the 99th percentile when compared to 40 years of data shows just how anomalous the event was in terms of PW magnitude and timing.

Another tool used to evaluate how anomalous the 2013 event was in terms of PW was to examine the PW frequency distributions. Foster et al. (2006) examined the monthly and annual frequency distributions of PW data for various stations and found that there were three main types of distributions for PW data: lognormal, which is the most common distribution around the world; reverse-lognormal, which represents an atmosphere near saturation; and bimodal, which occurs in regions with strong seasonal variability such as monsoonal zones.

To analyze PW frequency for this event, monthly distributions were created for June through September of 2004 2013 (Fig. 6). The skewness of each distribution was then calculated and these values, along with visual analysis, were used to determine whether each distribution was normal, lognormal, reverse-lognormal, or bimodal. Bulmer (1979) provided guidelines for interpreting the skewness of a distribution that were employed when evaluating the distributions in this study. A normal distribution has a skewness from -0.5 to 0.5 , while a positive (negative) skewness with its absolute values within 0.5 to 1 represents a lognormal (reverselognormal) distribution (Bulmer, 1979; Foster et al., 2006). 


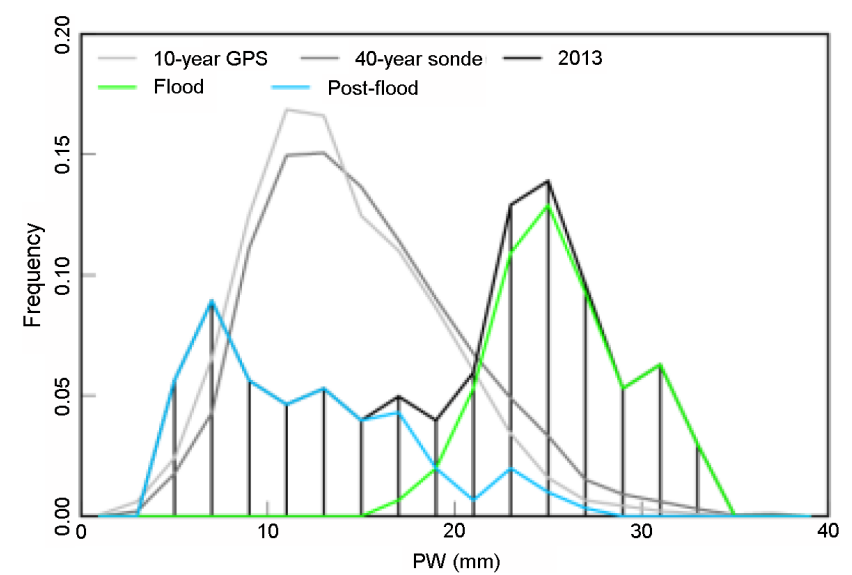

Figure 7. Statistical frequency distributions for the month of September with 2013 GPS PW data over Boulder (black line), 40 years of climatologically averaged radiosonde PW data over Denver (dark grey line), and 10 years of climatologically averaged GPS PW data over Boulder (light grey line). September 2013 GPS PW data was split into two halves: 1-15 September 2013 (flood; green line) and 16-30 September 2013 (post-flood; blue line).

Upon analyzing the distributions in Fig. 6, June through September primarily have normal distributions with September being, on average, slightly more positively skewed than the other months with a value of 0.32 , although the distribution is still considered normal according to the conditions for skewness defined in Bulmer (1979). However, the seasonal variation in PW is still evident as July and August distributions tend to have their highest frequencies over higher values of PW than either June or September. Also, despite most months having a normal distribution, there are four distributions which were labeled as lognormal because they have skewness values larger than 0.5: July 2005, September 2008, September 2010, and June 2013.

\section{Water vapor transport}

The occurrence of heavy precipitation such as was observed during the September 2013 event requires sufficient moisture supply to fuel it. In Sect. 3, PW was shown to spike rapidly prior to the flood and remain at highly anomalous values for the duration of the event. In order to more completely understand the PW characteristics of this event, it was important to investigate where the moisture originated and what mechanisms were controlling the moisture transport that kept the atmosphere very near to saturation for 7 consecutive days.

The moisture source and transport for the September 2013 event was briefly investigated in previous literature. Gochis et al. (2015) noted that the sources of moisture for the event were the Gulf of Mexico and the Tropical Eastern Pacific Ocean, both of which had $1-3{ }^{\circ} \mathrm{C}$ above normal sea surface temperature anomalies. They stated that the moisture from these regions was transported into the Front Range by a cutoff low over the southwestern United States (US) working in conjunction with an anticyclone over the southeastern US. Both of these features were kept in place for multiple days by a blocking ridge located over the Canadian Rockies (Gochis et al., 2015). Trenberth et al. (2015) stated that the source of moisture for the September 2013 event was only from the Tropical Eastern Pacific Ocean, while Mahoney et al. (2015) claimed the moisture for the event came primarily from the Gulf of Mexico.

The distribution that shows the largest shift in distribution from the other years is that of September of 2013, which had a bimodal distribution. Figure 7 shows a more detailed comparison of September of 2013 PW data with 10 years of GPS PW data and 40 years of radiosonde PW data. September of 2013 PW data were split up into two categories: "flood", which represents 1-15 September, and "post-flood", which represents 16-30 September. Figure 7 shows how different September of 2013 is from climatology and also how the atmosphere during the flood differed from the post-flood atmosphere. The atmosphere during the flood was highly saturated, with a peak frequency around $25 \mathrm{~mm}$ and PW values as high as $35 \mathrm{~mm}$. The frequency distribution during this time was normal with a skewness value of 0.175 . The post-flood atmosphere had a distinct lognormal distribution indicated by visual analysis and also by a skewness of 0.6838 . The atmosphere at this time was considerably drier, with frequency peaking at 0.9 around $7 \mathrm{~mm}$ of $\mathrm{PW}$.

Due to the slight variation of opinion on which body of water was the source of moisture for the event, this study further investigates moisture source and transport by examining NARR $500 \mathrm{hPa}$ geopotential height and integrated water vapor flux in conjunction with the standardized anomaly of gridded SuomiNet PW data. Five times surrounding the event were chosen for analysis based on their proximity to rapid fluctuations in PW, denoted by the vertical dashed lines in Fig. 3. The three variables listed above are plotted in Fig. 8 at each of the five time steps.

Figure $8 \mathrm{a}-\mathrm{c}$ show the atmospheric conditions on 6 September at 09:00 UTC, prior to the start of the event. There was a large ridge with $500 \mathrm{hPa}$ geopotential heights above $596 \mathrm{gpm}$ over the western half of the US (Fig. 8a), which contributed to higher temperatures and dried the atmosphere over Boulder as seen in Figs. 3 and 8c. At that point, there was no direct water vapor transport from either the Gulf of Mexico or the eastern Pacific (Fig. 8b).

Moving on to 9 September at 18:00 UTC (Fig. 8d-f), a trough started to form over the western US and an anticyclone shifted over the southeastern US (Fig. 8d). Together, these began transporting water vapor towards the northeast along the eastern flank of the trough from the eastern Pacific (Fig. 8e). This transport contributed to a belt of PW anomalies with magnitudes of 1.5-2.5 standard deviations over the southwestern and western US (Fig. 8f). The PW anomaly over Boulder at that point was between 1 and 1.5 standard de- 

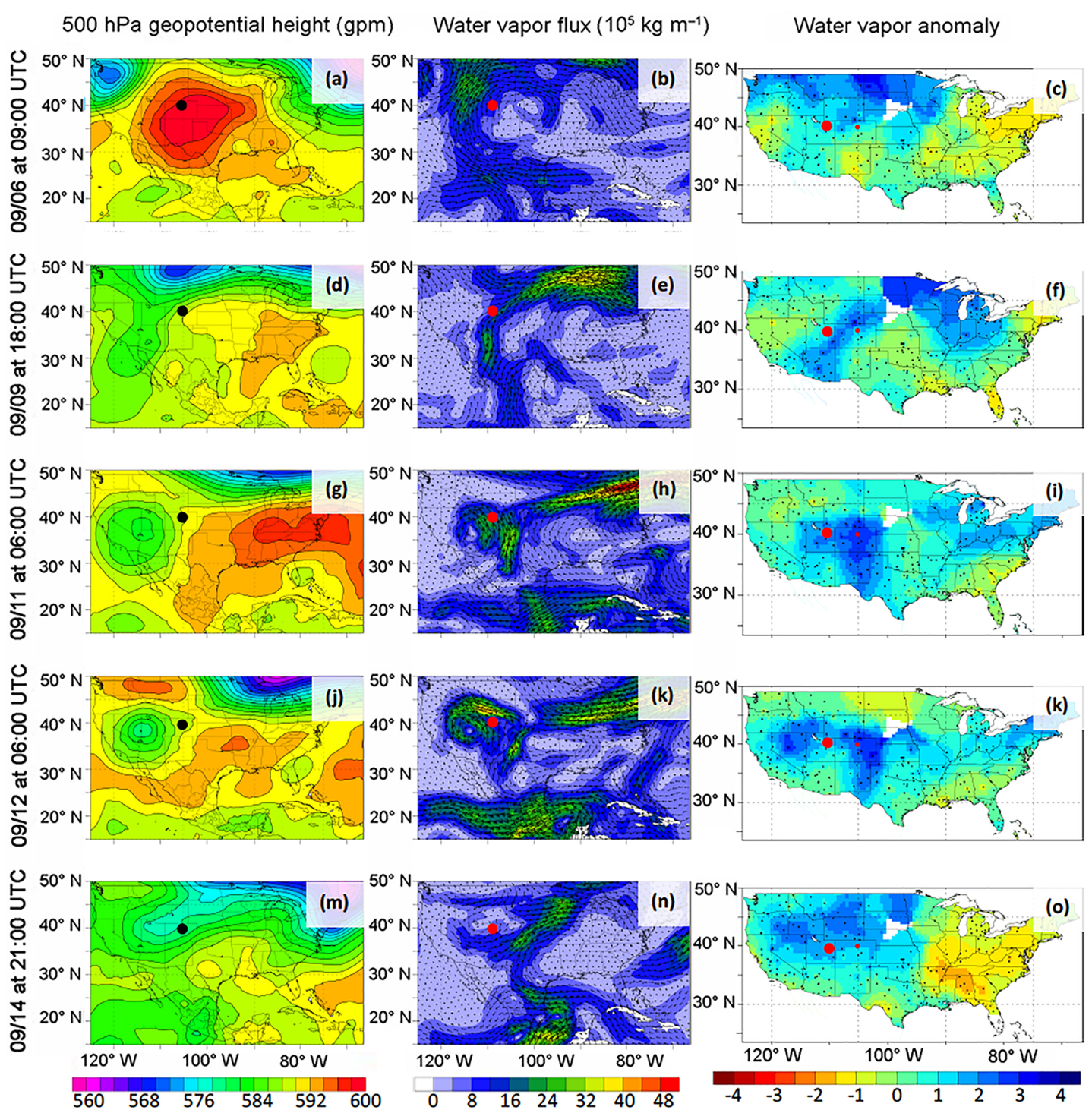

Figure 8. A comparison of NARR 3-hourly averaged $500 \mathrm{hPa}$ geopotential height (a, d, g, j, m), NARR 3-hourly averaged integrated water vapor flux (b, e, h, k, $\mathbf{n}$ ), and SuomiNet gridded standardized PW anomalies $(\mathbf{c}, \mathbf{f}, \mathbf{i}, \mathbf{k}, \mathbf{o})$. Each row represents a different time surrounding the 2013 event.

viations and precipitation had not yet begun (Fig. 3). At this point, $\mathrm{PW}$ values started to rise at a fairly quick rate (Fig. 3). This coincided with Adams et al. (2013), who found that water vapor increases by low-level moisture convergence due to large-scale or other forcings. Water vapor appeared to travel to Colorado from the Tropical Eastern Pacific at that time (Fig. 8e).

By 11 September at 06:00 UTC (Fig. 8g-i), the low pressure over the western US deepened and formed into a cutoff low (Fig. 8g). The low stagnated over the western US due to the influence of the blocking ridge under which it resided. The anticyclone over the eastern US also strengthened. Working in conjunction, the strengthening of the low and the high increased the southerly water vapor transport and there was a corridor of flux convergence over New Mexico and the direction of the flux over northern Colorado was toward the Rocky Mountains (Fig. 8h). This resulted in a corridor of PW anomalies that stretched from the Mexican border to southern Wyoming (Fig. 8i). The magnitude of the PW anomaly over Boulder rose to between 2.5 and 3 standard deviations as the moisture pooled against the Rocky Mountains due to easterly water vapor transport. Light, orographically enhanced precipitation began and Boulder experienced rain rates around $5 \mathrm{~mm} \mathrm{~h}^{-1}$ (Fig. 3). Water vapor was being transported into Colorado from the Tropical Eastern Pacific and the Gulf of Mexico at this time (Fig. 8h).

By 12 September at 06:00 UTC (Fig. 8j-1), the anticyclone began to break down but the cutoff low deepened even further 
(Fig. 8j). Water vapor was still being transported into the region from the Gulf of Mexico by the synoptic conditions with an easterly component of the flux continuing to pool water vapor against the Rocky Mountains (Fig. 8k). However, the transport of moisture into Colorado appeared to have weakened substantially and the Tropical Eastern Pacific was no longer a source of moisture. There was still a corridor of PW anomalies coinciding with the regions of strong water vapor flux and the magnitude of the anomaly over Boulder was still between 2.5 and 3 standard deviations (Fig. 81). Precipitation intensified over the past $24 \mathrm{~h}$ and Boulder experienced up to $35 \mathrm{~mm} \mathrm{~h}^{-1}$ of rainfall (Fig. 3). While a majority of the rainfall was orographically enhanced, the occasional intense periods of rainfall were a result of mesoscale circulations, as was noted by Gochis et al. (2015).

By 14 September at 21:00 UTC (Fig. 8m-o), the blocking ridge broke down, which allowed synoptic conditions to shift eastward, and the cutoff low once again became a trough (Fig. 8m). This resulted in the water vapor flux also shifting eastward (Fig. 8n). The PW anomaly over Boulder decreased to between 1 and 2 standard deviations (Fig. 8o). Rainfall for the event ended at this point, excluding a peak that occurred during the afternoon of 15 September (Fig. 3).

Upon comparing NARR integrated moisture flux with $500 \mathrm{hPa}$ geopotential height and observed standardized PW anomalies, it was found that the strength and location of moisture transport varied over the course of the event. Prior to the event, on 9 September, moisture from the Tropical Eastern Pacific appears to have been transported up to Colorado by a stagnating cutoff low over the southwestern US. Starting on 10 September, the cutoff low and subtropical anticyclone promoted southerly flow into Colorado from the Tropical Eastern Pacific and the Gulf of Mexico. As of 12 September, the Tropical Eastern Pacific no longer provided moisture for the event and the Gulf of Mexico was the sole source of moisture. By 14 September, the transport of moisture into Colorado had significantly weakened due to the eastward shift of the synoptic pattern. The moisture transport was dependent on the strength and location of the dominant synoptic features, and based on the analysis shown in Fig. 8 the moisture has been transported into Colorado from both the Tropical Eastern Pacific and the Gulf of Mexico. These results are most consistent with the findings of Gochis et al. (2015) but do not discount the results found in Trenberth et al. (2015) and Mahoney et al. (2015).

\section{Conclusions}

The aim of this research was to analyze PW characteristics surrounding the September 2013 event and compare them to climatology. Precipitation began approximately an hour after PW rose to between 2 and 3 standard deviations above the PW long-term median. This result was consistent with past literature that examined the relationship between PW and precipitation. Monthly-averaged PW values in the GPS dataset for September 2013 were above the 99th percentile when compared to the climatological data as well as around $25 \%$ higher than the monthly-averaged climatological mean value for September. That the monthly average for September of 2013 was so far above the climatology for 10 and 40 years of data indicates how anomalous the atmospheric moisture content was during the event. The frequency distribution of PW for September of 2013 was bimodal, which was much different than the typical normal distribution observed in September of other years. Upon further analysis, it was noted that the highly saturated portion of the bimodal distribution was solely the result of the September 2013 event, which had a nearly saturated atmosphere. The second half of September had a lognormal distribution, representing a much drier atmosphere for the rest of the month. The moisture for the event originated from the Tropical Eastern Pacific at the beginning of the event on 9 September came from this source and the Gulf of Mexico during the heaviest precipitation (1012 September), and then from only the Gulf of Mexico towards the end (12-14 September).

Code availability. Code is available from the lead author upon request.

Data availability. Two-hourly GPS PW data are available upon request from the first and second authors. Thirty-minute SuomiNet GPS PW data are available for download in ASCII and NetCDF format from the COSMIC group website (suominet.ucar.edu). The twice-daily, homogenized radiosonde data are available upon request from the second author. NARR data are available for download on the National Oceanic and Atmospheric Administration (NOAA) website (nomads.ncdc.noaa.gov/data/narr). The 1-hourly rain gauge data are available upon request from the National Center for Atmospheric Research (NCAR) Research Applications Laboratory (RAL).

Author contributions. The first author was the primary researcher with constant assistance and guidance from the second author. The third author was the PI on the grant and a contributing editor. The fourth author served as an editor.

Competing interests. The authors declare that they have no conflict of interest.

Special issue statement. This article is part of the special issue "Advanced Global Navigation Satellite Systems tropospheric products for monitoring severe weather events and climate (GNSS4SWEC) (AMT/ACP/ANGEO inter-journal SI)". It is not associated with a conference. 
Acknowledgements. This research was supported by the National Aeronautics and Space Administration (NASA) RSS subcontract no. 6003 under the prime contract NNX11AO25A. The authors would like to thank David K. Adams and the anonymous reviewers for their valuable input during the review process.

Edited by: Roeland Van Malderen

Reviewed by: David Adams and two anonymous referees

\section{References}

Adams, D. K., Gutman, S. I., Holub, K. L., and Pereira, D. S.: GNSS Observations of Deep Convective Time scales in the Amazon, Geophys. Res. Lett., 40, 2818-2823, https://doi.org/10.1002/grl.50573, 2013.

Bohling, G.: Introduction to geostatistics and variogram analysis C\&PE 940, Kansas Geological Survey, USA, 2005.

Bulmer, M. G.: Principles of Statistics, M.I.T. Press, Cambridge, MA, USA, 1979.

Colorado Climate Center, Colorado Flood 2013 Storm Page, available at: http://coflood2013.colostate.edu/ (last access: October 2017), October 2013.

Dai, A., Wang, J., Thorne, P. W., Parker, D. E., Haimberger, L., and Wang, X. L.: A new approach to homogenize daily radiosonde humidity data, J. Climate, 24, 965-991, 2011.

Foster, J., Bevis, M., Chen, Y.-L., Businger, S., and Zhang, Y.: The Ka'ù Storm (November 2000): Imaging precipitable water using GPS, J. Geophys. Res., 108, 4585, https://doi.org/10.1029/2003JD003413, 2003.

Foster, J., Bevis, M., and Raymond, W.: Precipitable water and the lognormal distribution, J. Geophys. Res., 111, D15102, https://doi.org/10.1029/2005JD006731, 2006.

Gimeno, L., Stohl, A., Trigo, R. M., Dominguez, F., Yoshimura, K., Yu, L., Drumond, A., Durán-Quesada, A. M., and Nieto, R.: Oceanic and terrestrial sources of continental precipitation, Rev. Geophys., 50, RG4003, https://doi.org/10.1029/2012RG000389, 2012.

Gochis, D., Schumacher, R., Friedrich, K., Doesken, N., Kelsch, M., Sun, J., Ikeda, K., Lindsey, D., Wood, A., Dolan, B., Matrosov, S., Newman, A., Mahoney, K., Rutledge, S., Johnson, R., Kucera, P., Kennedy, P., Sempere-Torres, D., Steiner, M., Roberts, R., Wilson, J., Yu, W., Chandrasekar, V., Rasmussen, R., Anderson, A., and Brown, B.: The Great Colorado Flood of September 2013, B. Am. Meteorol. Soc., 96, 1461-1487, https://doi.org/10.1175/BAMS-D-13-00241.1, 2015.

Graham, E., Koffi, E. N., and Matzler, C.: An observational study of air and water vapour convergence over the western Alps during summer and the development of isolated thunderstorms, Meteorol. Z., 21, 1-13, https://doi.org/10.1127/0941-2948/2012/0347, 2012.

Grumm, R. H. and Hart, R.: Standardized anomalies applied to significant cold season weather events: Preliminary findings, Weather Forecast., 16, 736-754, 2001.

Guerova, G., Jones, J., Douša, J., Dick, G., de Haan, S., Pottiaux, E., Bock, O., Pacione, R., Elgered, G., Vedel, H., and Bender, M.: Review of the state of the art and future prospects of the groundbased GNSS meteorology in Europe, Atmos. Meas. Tech., 9, 5385-5406, https://doi.org/10.5194/amt-9-5385-2016, 2016.
Hoerling, M., Wolter, K., Perlwitz, J., Quan, X., Eischeid, J., Wang, H., Schubert, S., Diaz, H., and Dole, R.: Northeast Colorado extreme rains interpreted in a climate change context, in: Explaining Extremes of 2013 from a Climate Perspective, B. Am. Meteorol. Soc., 95, S15-S18, 2014.

Karl, T. R. and Trenberth, K. E.: Modern global climate change, Science, 302, 1719-1723, 2003.

Kunkel, K. E., Karl, T. R., Brooks, H., Kossin, J., Lawrimore, J. H., Arndt, D., Bosart, L., Changnon, D., Cutter, S. L., Doesken, N., Emanuel, K., Groisman, P. Y., Katz, R. W., Knutson, T., O’Brien, J., Paciorek, C. J., Peterson, T. C., Redmond, K., Robinson, D., Trapp, J., Vose, R., Weaver, S., Wehner, M., Wolter, K., and Wuebbles, D.: Monitoring and understanding trends in extreme storms: State of knowledge, B. Am. Meteorol. Soc., 94, 499-514, 2013.

Maddox, R. A., Caracena, F., Hoxit, L. R., and Chappell, C. F.: Meteorological Aspects of the Big Thompson Flash Flood of 31 July 1976, NOAA, Boulder, CO, Technical Report ERL 388APCL41, 1977.

Mahoney, K., Ralph, F. M., Wolter, K., Doesken, N., Dettinger, M., Gottas, D., Coleman, T., and White, A.: Climatology of Extreme Daily Precipitation in Colorado and Its Diverse Spatial and Seasonal Variability, J. Hydrometeorol., 16, 781-792, https://doi.org/10.1175/JHM-D-14-0112.1, 2015.

McKee, T. B. and Doesken, N. J. : Final report: Colorado extreme precipitation data study, Colorado Climate Center, Department of Atmospheric Science, Colorado State University, Fort Collins, USA, Climatology Report 97-1, 107 pp., 1997.

Mears, C., Ho, S., Peng, L., Wang, J., and Huelsing, H.: Total column PW, in: State of the Climate in 2014, B. Am. Meteorol. Soc., 96, S22-S23, 2015.

Mears, C., Ho, S., Wang, J., Huelsing, H., and Peng, L.: Total Column Water Vapor, in: State of the Climate in 2016, B. Am. Meteorol. Soc., 98, S24-S25, https://doi.org/10.1175/2017BAMSStateoftheClimate.1, 2017.

Mesinger, F., DiMego, G., Kalnay, E., Mitchell, K., Shafran, P .C., Ebisuzaki, W., Jović, D., Woollen, J., Rogers, E., Berbery, E. H., Ek, M. B., Fan, Y., Grumbine, R., Higgins, W., Li, H., Lin, Y., Manikin, G., Parrish, D., and Shi, W.: North American Regional Reanalysis, B. Am. Meteorol. Soc., 87, 343-360, 2006.

Petersen, W. A., Carey, L. D., Rutledge, S. A., Knievel, J. C., Johnson, R. H., Doesken, N. J., McKee, T. B., Vonder Haar, T., and Weaver, J. F.: Mesoscale and Radar Observations of the Fort Collins Flash Flood of 28 July 1997, B. Am. Meteorol. Soc., 80, 191-216, 1999.

Sapucci, L. F., Machado, L. A. T., Menezes de Souza, E., and Campos, T. B.: GPS-PWV jumps before intense rain events, Atmos. Meas. Tech. Discuss., https://doi.org/10.5194/amt-2016378, 2016.

Trenberth, K. E., Fasullo, J. T., and Shepherd, T. G.: Attribution of climate extreme events, Nature Climate Change, 5, 725-730, 2015.

Van Baelen, J., Reverdy, M., Tridon, F., Labbouz, L., Dick, G., Bender, M., and Hagen, M.: On the relationship between water vapour and evolution and the life cycle of precipitation systems, Q. J. Roy. Meteor. Soc., 137, 204-223, https://doi.org/10.1002/qj.785, 2011. 
Wang, J., Zhang, L., Dai, A., Van Hove, T., and Van Baelen, J.: A near-global, 2- hourly dataset of atmospheric precipitable water from ground-based GPS measurements, J. Geophys. Res., 112, D11107, https://doi.org/10.1029/2006JD007529, 2007

Ware, R. H., Fuller, D. W., Stein, S. A., Anderson, D. N., Avery, S. K., Clark, R. D., Droegemeier, K. K., Kuettner, J. P., Minster, J. B., and Sorooshian, S.: SuomiNet: A Real-Time National Network for Atmospheric Research and Education, B. Am. Meteorol. Soc., 81, 677-694, 2000.
Yasrebi, J., Saffari, M., Fathi, H., Karimian, N., Moazallahi, M., and Gazni, R.: Evaluation and comparison of ordinary kriging and inverse distance weighting methods for prediction of spatial variability of some soil chemical parameters, Research Journal of Biological Sciences, 4, 93-102, 2009.

Zimmerman, D., Pavlik, C., Ruggles, A., and Armstrong, M. P.: An experimental comparison of ordinary and universal Kriging and inverse distance weighting, Math. Geol., 31, 375-390, 1999. 